\section{A) Check for updates}

Cite this: Dalton Trans., 2020, 49, 16736
Received 24th September 2020, Accepted 21st October 2020

DOI: $10.1039 / \mathrm{d} 0 \mathrm{dt} 03325 \mathrm{a}$

rsc.li/dalton

\title{
Alkaline earth-organic frameworks with amino derivatives of 2,6-naphthalene dicarboxylates: structural studies and fluorescence properties $\uparrow$
}

\author{
Stavros A. Diamantis, (D) ${ }^{a}$ Antonios Hatzidimitriou, ${ }^{a}$ Alexios K. Plessas, (D) ${ }^{b}$ \\ Anastasia Pournara, ${ }^{C}$ Manolis J. Manos, (D) c Giannis S. Papaefstathiou (D) *b and \\ Theodore Lazarides (iD *a
}

\begin{abstract}
Alkaline earth metal ion organic frameworks (AEMOFs) represent a relatively underexplored subcategory of metal-organic frameworks (MOFs). In this contribution, we present the synthesis and structural study of the new MOFs 1-8 based on the alkaline earth ions $\mathrm{Mg}^{2+}, \mathrm{Ca}^{2+}, \mathrm{Sr}^{2+}$ and $\mathrm{Ba}^{2+}$ and the amino substituted bridging ligands 4-aminonaphthalene-2,6-dicarboxylate (ANDC ${ }^{2-}$ ) and 4,8-diaminonaphthalene2,6-dicarboxylate (DANDC ${ }^{2-}$ ). Compounds 1, 5, 6, 7 and 8 constitute rare examples of three-dimensional MOFs which feature square planar $M_{4}$ secondary building units (SBUs) surrounded by eight bridging ditopic ligands. The underlying topology of MOFs 1, 5, 7 and $\mathbf{8}$ conforms to the 4-c pcb net which can be simplified to the 8-c bcu net, while 6 adopts the 4-c lta net which simplifies to the 8-c reo net. To the best of our knowledge these are the first examples of MOFs of their structural types formed by linear dicarboxylates instead of trigonal tricarboxylates or tetrahedral tetracarboxylates. Compounds 2, $\mathbf{3}$ and $\mathbf{4}$ also feature three dimensional networks with linear rod-shaped SBUs with the $\mathrm{Ba}^{2+}$ MOF 3 displaying an sra rod-net and MOFs 2 and $\mathbf{4}$ showing very complex rod-nets with so far unique topologies. Fluorescence studies revealed that the free ligands exhibit strong blue-green emission displaying considerable positive solvatochromism thereby pointing towards charge transfer excited states involving the shift of electron density from the amino groups to the aromatic core. Correspondingly, the MOFs display ligand based fluorescence with small differences in emission maxima possibly attributable to the difference in the charge density of the metal ions combined with the different environments around ligands in the crystal structures.
\end{abstract}

\section{Introduction}

Metal-organic frameworks (MOFs) constitute a unique class of porous (or potentially porous) materials which are characterized by two or three-dimensional open network structures consisting of nodes in the form of metal centres (either single ions or clusters) which are interconnected by bridging poly-

\footnotetext{
${ }^{a}$ Laboratory of Inorganic Chemistry, Department of Chemistry, Aristotle University of Thessaloniki, Thessaloniki, 54124, Greece.E-mail: tlazarides@chem.auth.gr

${ }^{b}$ Laboratory of Inorganic Chemistry, Department of Chemistry, National and Kapodistrian University of Athens, Panepistimiopolis, Zografou 15771, Greece. E-mail: gsppaef@chem.uoa.gr

${ }^{c}$ Laboratory of Inorganic Chemistry, Department of Chemistry, University of Ioannina, Ioannina 45110, Greece

$\dagger$ Electronic supplementary information (ESI) available: Ligand and AEMOFs synthesis, NMR spectra and ESI-MS data of the $\mathrm{H}_{2}$ DANDC ligand, thermal analyses data, single crystal and powder X-ray diffraction data, excitation and absorption UV-vis spectra. CCDC 2033666-2033673. For ESI and crystallographic data in CIF or other electronic format see DOI: $10.1039 /$ d0dt03325a
}

dentate organic ligands. ${ }^{1-3}$ MOFs are intensely investigated due to their structural and functional variety which makes them attractive for a plethora of applications such as gas storage and separation, ${ }^{4-8}$ catalysis, ${ }^{9-15}$ ion sorption and exchange $^{14,16-19}$ and more recently as chemical sensors. ${ }^{16,20-26}$

In comparison to d-block and rare earth metal ions, research on alkaline earth MOFs (AEMOFs) is still on a rather preliminary level. ${ }^{27}$ The closed-shell electronic structure of alkaline earth ions results in their MOFs exhibiting ligandbased fluorescence ${ }^{28-30}$ which, in the cases where ligands contain suitable functional groups, can prove to be of interest for possible sensing applications. ${ }^{31-33}$ In addition, there are examples of AEMOFs which show promising gas separation, $^{34,35}$ catalytic $^{36,37}$ and electrical properties. ${ }^{38-42}$ Amino functionalized aromatic dicarboxylates are of particular interest for MOF synthesis as they can lead to materials with increased $\mathrm{CO}_{2}$ adsorption ${ }^{43}$ and favorable fluorescence ${ }^{44}$ and photocatalytic $^{45-48}$ properties. However, the chemistry of amino functionalized MOFs is largely dominated by the 


\section{$\left[\mathrm{Ca}_{4}\left(\mu_{4}-\mathrm{H}_{2} \mathrm{O}\right)(\mathrm{ANDC})_{4}(\mathrm{DMF})_{4}\right] \cdot 6 \mathrm{DMF}(\mathbf{1})$}

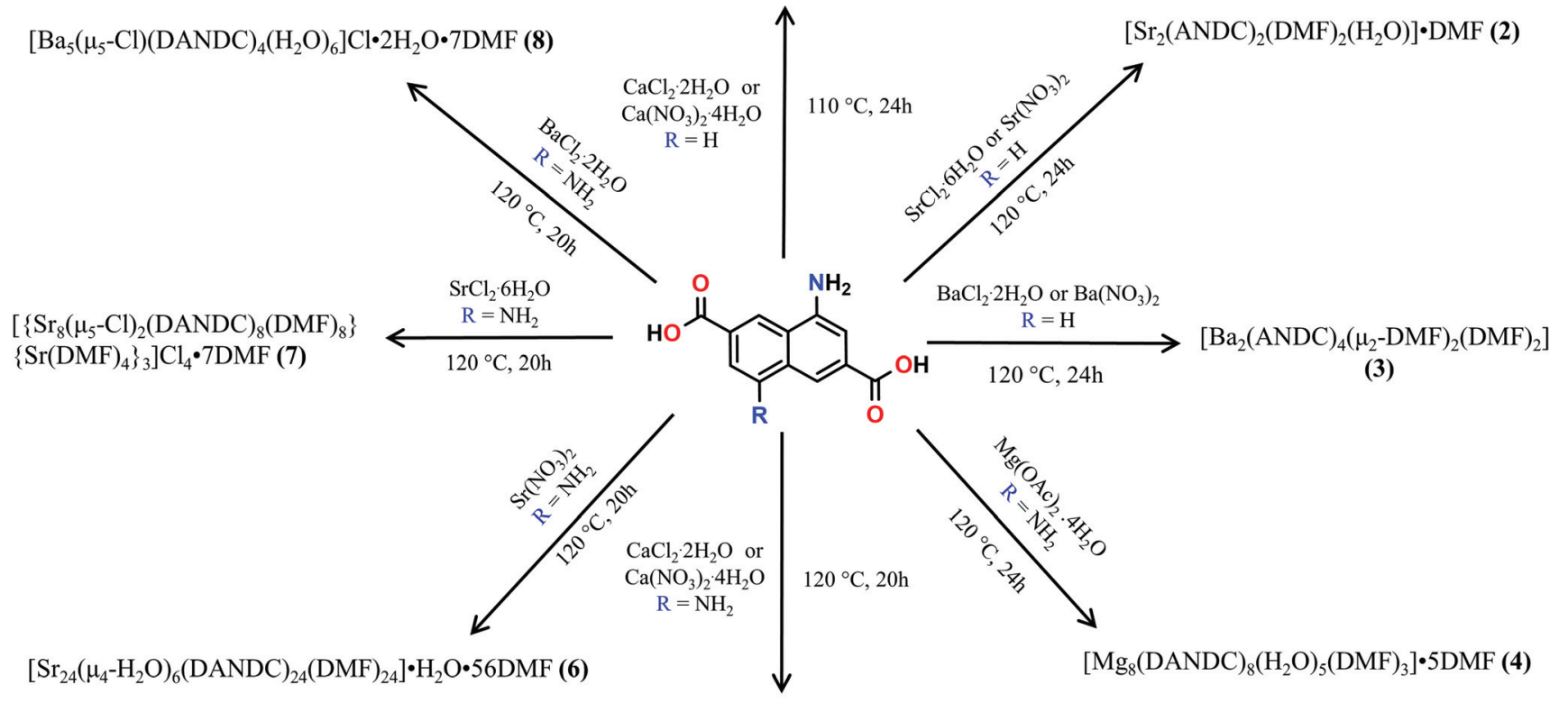

$\left[\mathrm{Ca}_{4}\left(\mu_{4}-\mathrm{H}_{2} \mathrm{O}\right)(\mathrm{DANDC})_{4}\left(\mathrm{H}_{2} \mathrm{O}\right)_{3}(\mathrm{DMF})\right] \cdot 2 \mathrm{H}_{2} \mathrm{O} \cdot 4 \mathrm{DMF}$ (5)

Scheme 1 Synthetic routes leading to compounds 1-8.

2-amino-1,4-benzenedicarboxylate $\left(\mathrm{NH}_{2} \mathrm{BDC}^{2-}\right)$ and 5-amino1,3-dicarboxylate ligands and their derivatives ${ }^{43,49}$ with only relatively few examples involving ligands with longer naphthalene or biphenyl spacers. ${ }^{47,50-58}$

In this contribution, we report the synthesis and structural and photophysical study of AEMOFs 1-8 (Scheme 1) which are based on the amino-substituted dicarboxylic bridging ligands 4-aminonaphthalene-2,6-dicarboxylate $\left(\mathrm{ANDC}^{2-}\right)^{55}$ and 4,8-diaminonaphthalene-2,6-dicarboxylate (DANDC ${ }^{2-}$ ). A synthesis of the latter ligand through the catalytic hydrogenation of 4,8dinitro-2,6-naphthalene dicarboxylic acid $^{59}$ is also reported here. The AEMOFs form open three-dimensional frameworks and display remarkable structural features with, in some cases, unique network topologies and metal secondary building units (SBUs) ranging from infinite rods to rarely observed tetranuclear square planar clusters. ${ }^{60-64}$ The UV-vis absorption and fluorescence spectra of the free ligands $\mathrm{H}_{2}$ ANDC and $\mathrm{H}_{2}$ DANDC show significant solvatochromism which is consistent with charge transfer excited states. The corresponding AEMOFs exhibit ligand-based blue-green fluorescence at room temperature.

\section{Results and discussion}

The reactions of alkaline earth metal salts with $\mathrm{H}_{2}$ ANDC and $\mathrm{H}_{2}$ DANDC ligands in dimethylformamide (DMF) containing $10 \%(\mathrm{v} / \mathrm{v})$ water at $110-120{ }^{\circ} \mathrm{C}$ afforded a series of crystalline products 1-8, the formulas of which, as determined by single crystal X-ray crystallographic analysis, can be seen in Scheme 1. All the compounds were found to possess three- dimensional network structures which are described in detail in the following sections. Tables containing crystallographic details and selected bond angles and distances for each structure can be found in ESI (Tables S1-10†).

\section{Crystal structures of $1,5,7$ and 8}

These MOFs crystallize in the tetragonal $I 4 / \mathrm{m}$ space group (Tables S1 and $2 \dagger$ ) and their structures are based on tetranuclear SBUs $\mathrm{M}_{4}(\mathrm{COO})_{8}(\mathrm{M}=\mathrm{Ca}$ for 1 and 5 ; $\mathrm{Sr}$ for 7 ; Ba for 8), with the metal ions arranged on the corners of a square and being held together by eight chelating, bridging $\mu_{2}-\eta^{2}: \eta^{1}$ carboxylate groups four of which are above and four below the square plane. It is worth noting that, square $\mathrm{M}_{4}$ SBUs are relatively rare compared to those where the four metal atoms are in a tetrahedral arrangement and have mainly been observed with divalent transition metal ions such as $\mathrm{Cu}^{62}$ and $\mathrm{Cd}^{63}$ and trivalent lanthanides. ${ }^{64}$ To the best of our knowledge, there is only one example of a MOF with a square $\mathrm{Ca}_{4} \mathrm{O}$ SBU which involves the tetrahedral tetracarboxylic ligand methanetetrabenzoate (MTB). ${ }^{34,60}$ In our compounds, the centre of the $\mathbf{M}_{4}$ square is occupied by a disordered water molecule in the cases of the $\mathrm{Ca}^{2+}$ MOFs 1 and 5 (Fig. 1A) or by a chloride anion in the cases of the $\mathrm{Sr}^{2+}$ and $\mathrm{Ba}^{2+}$ MOFs 7 and 8 (Fig. $\mathrm{S} 14 \mathrm{~A} \dagger$ and Fig. 1C respectively). Each of the four $\mathrm{M}^{2+}$ ions is eight coordinated by six carboxylic oxygen atoms, one water molecule (1 and 5) or one $\mathrm{Cl}^{-}$ion (7 and 8) and one terminal DMF (1, 5 and 7 ) or water (8) ligand. The coordination polyhedron about the metal ion can be best described as a distorted square antiprism. In the cases of the compounds involving the larger $\mathrm{Sr}^{2+}$ and $\mathrm{Ba}^{2+}$ ions (7 and 8 ), the four bridging carboxylic oxygen 
A)

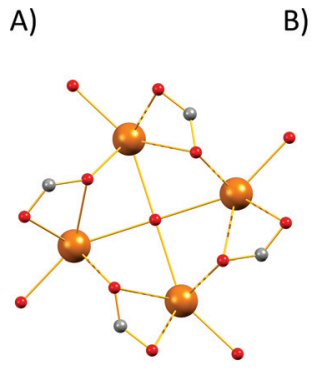

C)

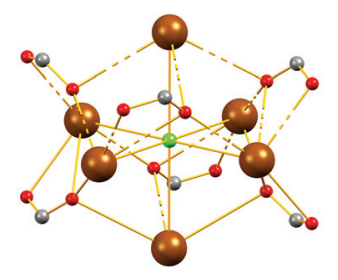

D)
B)

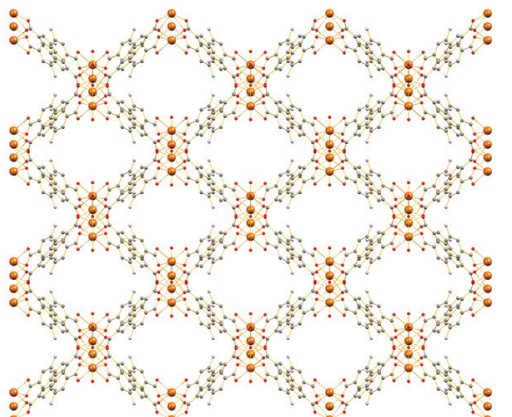

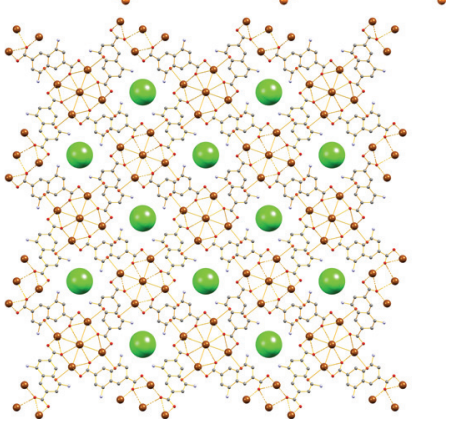

Fig. 1 Representation of the (A) tetranuclear SBU of 1; (B) three-dimensional structure along the $b$ axis of 1 ; (C) metal core of 8 and (D) threedimensional structure along the $c$ axis of $\mathbf{8}$, the chloride counter-ions are displayed in space-filling mode. $\mathrm{H}$ atoms and solvent molecules are omitted for clarity. Colour code: Ca, brown; Ba dark brown; C, gray; O, red; $\mathrm{N}$, blue; $\mathrm{Cl}$, green.

atoms residing above the square $\mathrm{M}_{4}$ plane, together with their four counterparts residing below the latter, create two oxygenrich "nests" which are partially occupied by $\mathrm{M}^{2+}$ cations thereby creating $\mathrm{M}_{6}$ octahedra. The extra positive charge which is introduced in $\mathbf{7}$ and $\mathbf{8}$ is balanced by $\mathrm{Cl}^{-}$counter ions which are located in the centre of the $\mathrm{M}_{4}$ square plane and in the cavities of the MOFs. It is worth mentioning that in the case of the smaller $\mathrm{Sr}^{2+}$ ion (7) we observe disorder in both the $\mathrm{Cl}^{-}$ anion and the carboxylic oxygen atoms which are involved in bonding with the axial metal ions (Fig. S14 $\uparrow$ ). The distances between the metal ions and the carboxylate oxygens range from 2.252 to $2.882 \AA$. The bond length between the $\mathrm{Ca}^{2+}$ ions and the oxygen atom of the central $\mathrm{H}_{2} \mathrm{O}$ molecule were found to be 2.564 and $2.670 \AA$ in $\mathbf{1}$ and $\mathbf{5}$ respectively. The considerably larger distances observed in the case of $\mathbf{5}$ possibly reflect the higher steric demand of the DANDC ${ }^{2-}$ bridging ligand. In the case of $\mathbf{8}$, the distance between the metal ions of the $\mathrm{M}_{4}$ plane and the bridging chloride ions was found to be $3.123 \AA$. The crystal structures of 7 and $\mathbf{8}$ are stabilized by strong hydrogen bonds between the amino groups of the dicarboxylate linker and (a) the chloride counter ions (2.393-2.552 ̊) and (b) the carboxylate oxygen of a neighboring ligand (2.137-2.158 ̊).

The three-dimensional the structures of $\mathbf{1}, 5,7$ and 8 are formed by $\mathrm{M}_{4}$ SBUs surrounded by eight dicarboxylate ligands (Fig. 1B and D). It is worth mentioning that the structures of $\mathbf{1}$, 5,7 and 8 bear close resemblance to that observed in a fluor-

ite-like MOF reported by Kim and co-workers ${ }^{65}$ in 2004 which is constructed by square planar $\mathrm{Cd}_{4}$ SBUs (which are similar to the $\mathrm{M}_{4}$ SBUs presented here) interconnected by eight tetrahedral tetracarboxylate MTB ligands. To the best of our knowledge, structures 1, 5, 7 and 8 represent the first examples of this structural type with a linear dicarboxylate bridging ligand.

From the topological point of view, the $\mathrm{M}_{4}$ clusters in 1, 5, 7 and $\mathbf{8}$ are surrounded by eight different dicarboxylate ligands (one unique) that connect the central cluster to eight neighboring $\mathrm{M}_{4}$ clusters (Fig. S15 $\dagger$ ) The eight carboxylate $\mathrm{C}$ atoms around each $\mathrm{M}_{4}$ cluster form a rectangular prism with distances of $\sim 4$ to $5 \AA$. The vertices of the prism are connected through the naphthalene moieties of the ligands (C...C $\sim 8 \AA$ ) to produce a uninodal 4-coordinate pcb network with point symbol $\left(4^{3} \cdot 8^{3}\right)$. These MOF have been to found to adopt the exact same topology with other MOFs ${ }^{66-68}$ such as such as $\left[\mathrm{Zn}_{8}(\mathrm{Im})_{6}(\mathrm{MBIm})_{6}\right]^{4-},{ }^{69}$ and the hydrogen-bonded assemblies MOC- $2^{70}$ and $\mathrm{Co}^{(\mathrm{III}}{ }_{14}$-MOC. $^{71}$ Simplification of the pcb network by contracting the eight $\mathrm{C}$ atoms of each square prism to their centre of gravity produces a uninodal 8-coordinate bcu network with point symbol $\left(4^{24} \cdot 6^{4}\right)$, which has been observed in many MOFs (Fig. S15†). ${ }^{72-74}$

\section{Crystal structure of 6}

The $\mathrm{Sr}^{2+}$ MOF 6, which is not topologically equivalent to $1,5,7$ and $\mathbf{8}$, crystallizes in the cubic space group $F m \overline{3} c$ and its metal SBU is virtually identical to those observed in $\mathrm{Ca}^{2+}$ MOFs 1 and 5. However, it is worth noting that, to the best of our knowledge, 6 constitutes the first example of an SBU consisting of four $\mathrm{Sr}^{2+}$ ions in a square planar arrangement. As expected from the larger radius of $\mathrm{Sr}^{2+}$, the $\mathrm{Sr}-\mathrm{Sr}$ and $\mathrm{Sr}-\mathrm{O}$ distances within the $\mathrm{Sr}_{4}$ cluster of $\mathbf{6}$ are considerably larger than those of 5 (3.814 and $2.697 \AA$ respectively). Similarly to 1, 5, 7 and $\mathbf{8}$, the basic building unit of $\mathbf{6}$ is a square prism formed by the eight carboxylate $\mathrm{C}$ atoms around each $\mathrm{Sr}_{4}$ unit with the naphthalene moieties of the eight DANDC ${ }^{2-}$ ligands bridging the $\mathrm{Sr}_{4}$ SBUs (Fig. 2).

However, in contrast to the above described structures, the underlying network of $\mathbf{6}$ is different. Owing to the different symmetry of the structure, the orientation and the connectivity of the square prisms is slightly different resulting also in a 4-c net but with the three letter code lta and point symbol $\left(4^{3} \cdot 6^{2} \cdot 8\right) \cdot{ }^{75-78}$ As expected, the simplification of the lta net by contracting the eight $\mathrm{C}$ atoms of each square prism to their centre of gravity produces a uninodal 8-coordinate reo network with point symbol $\left(3^{8} \cdot 4^{8} \cdot 5^{8} \cdot 6^{4}\right)$, which has been observed in many MOFs (Fig. S16†). ${ }^{79-81}$

\section{Crystal structure of 2}

Compound 2 crystallizes in the monoclinic space group $P 2_{1} / c$ (Table S1 $\dagger$ ) and features a three-dimensional framework with two crystallographically unique $\mathrm{Sr}^{2+}$ ions $(\mathrm{Sr} 1, \mathrm{Sr} 2)$. The structure of 2 is based on an infinite twisted rod SBU $\left[\mathrm{Sr}_{2}(\mathrm{COO})_{4}(\mathrm{DMF})_{2}\left(\mathrm{H}_{2} \mathrm{O}\right)\right]_{\infty}$. Both $\mathrm{Sr}^{2+}$ ions are eight coordinated and the coordination polyhedron around them is best described as a biaugmented triangular prism. The Sr1 ion is 


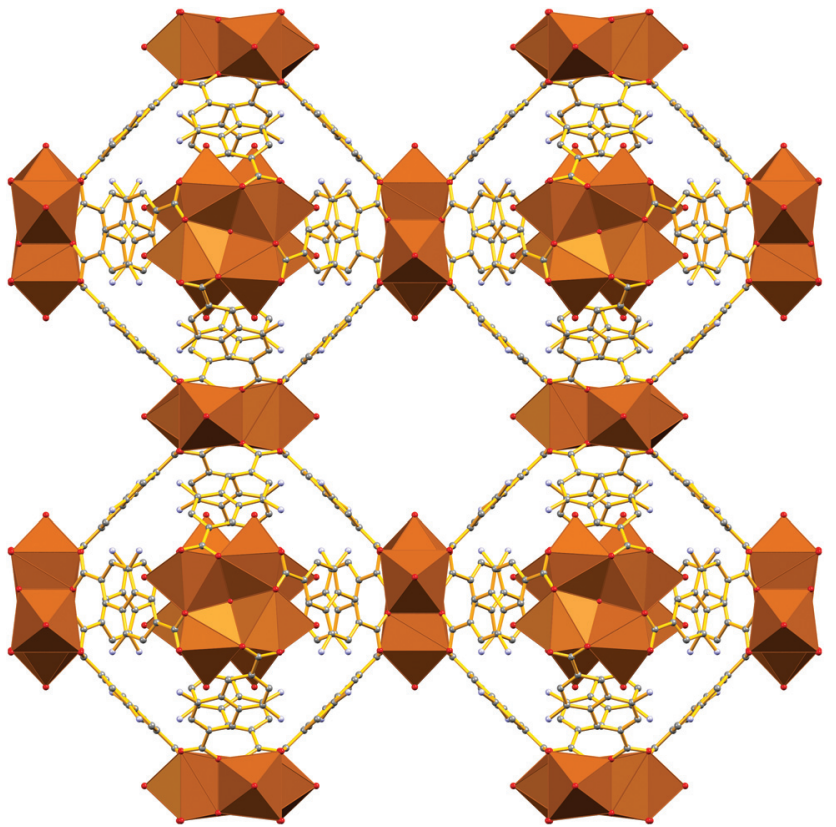

Fig. 2 Representation of the three-dimensional structure of 6. $\mathrm{H}$ atoms and solvent molecules were omitted for clarity. Colour code: $\mathrm{Sr}$, brown; $\mathrm{C}$, gray; $\mathrm{O}$, red; $\mathrm{N}$, blue.

ligated to six carboxylate oxygen atoms, one water molecule and a terminal DMF ligand (Fig. 3). On the other hand, the coordination sphere of Sr2 contains seven carboxylate oxygen atoms and one oxygen atom from a terminal DMF molecule.

The carboxylate groups in 2 bridge the Sr atoms to create a twisted chain (rod) of alternate face and edge-sharing biaugmented triangular prisms running parallel to the $c$ axis (Fig. S17†). If we consider the carboxylate C atoms (C1, C12, $\mathrm{C} 13$, and $\mathrm{C} 19)$ as the points of connection, then a corner- sharing ladder of distorted square pyramids forms along the rod. The distorted square pyramids have one more corner linked and their apexes point almost to the same side of the rod. These ladders are further linked by the naphthalene moities of the ligands to create a complex tetranodal network comprising three 5 -coordinate and one 7 -coordinate node. The point symbol of this net is $\left(3^{3} \cdot 4^{2} \cdot 5 \cdot 7^{3} \cdot 8\right)\left(3^{3} \cdot 4^{2} \cdot 5^{3} \cdot 6^{2}\right)\left(3^{4} \cdot 4^{2} \cdot 8^{4}\right)$ $\left(3^{5} \cdot 4^{4} \cdot 5^{5} \cdot 6^{5} \cdot 7^{2}\right)$ and it is, as expected, unique so far.

\section{Crystal structure of 3}

Representation of the SBU and the three-dimensional structure of 3 are shown in Fig. 4. Compound 3 crystallizes in monoclinic space group $P 2_{1} / n$ (Table $\mathrm{S} 1 \dagger$ ). The structure of 3 is based on an infinite rod $\mathrm{SBU} \mathrm{Ba}_{2}(\mathrm{COO})_{4}\left(\mu_{2}-\mathrm{DMF}\right)_{2}(\mathrm{DMF})_{2}$ in which there are two crystallographically unique $\mathrm{Ba}^{2+}$ (Ba1, Ba2) ions. Both $\mathrm{Ba}^{2+}$ ions are nine-coordinated, with the coordination polyhedron around them being best described as muffin-like. Each $\mathrm{Ba}^{2+}$ is ligated to six carboxylate oxygen atoms, two $\mu_{2}-$ brigding DMF molecules and a terminal DMF ligand.

Topologically, the carboxylate groups bridge the Ba1 atoms to create a chain (rod) of alternate edge sharing Ba1 muffins running parallel to the $b$ axis (Fig. S18†). A very similar situation is found for the second $\mathrm{Ba} 2$ atom, a rod of face sharing $\mathrm{Ba} 2$ muffins forms along $b$ axis, parallel to the previous Ba1 rod. If we consider the carboxylate $\mathrm{C}$ atoms ( $\mathrm{C} 1$ and $\mathrm{C} 24$ for $\mathrm{Ba} 1$ and $\mathrm{C} 12$ and $\mathrm{C} 13$ for $\mathrm{Ba} 2$ ) as the points of connection, then a ladder forms along the Ba1 rod and a second ladder forms along the $\mathrm{Ba} 2$ rod. These ladders are further linked by the naphthalene moities of the ligands such that each Ba1 rod being surrounded by four Ba2 rods and vice versa. Therefore, a uninodal 4-coordinate network is formed with three-letter code sra and point symbol $\left(4^{2} \cdot 6^{3} \cdot 8\right)$. The same sra rod-net has been observed in several MOFs. ${ }^{82-84}$
A)

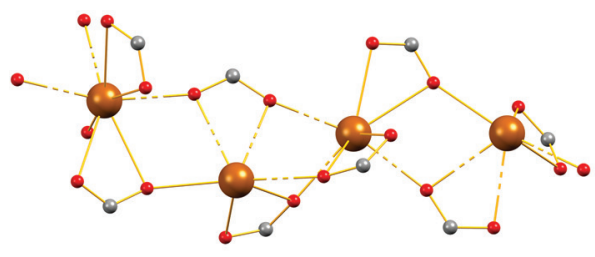

B)

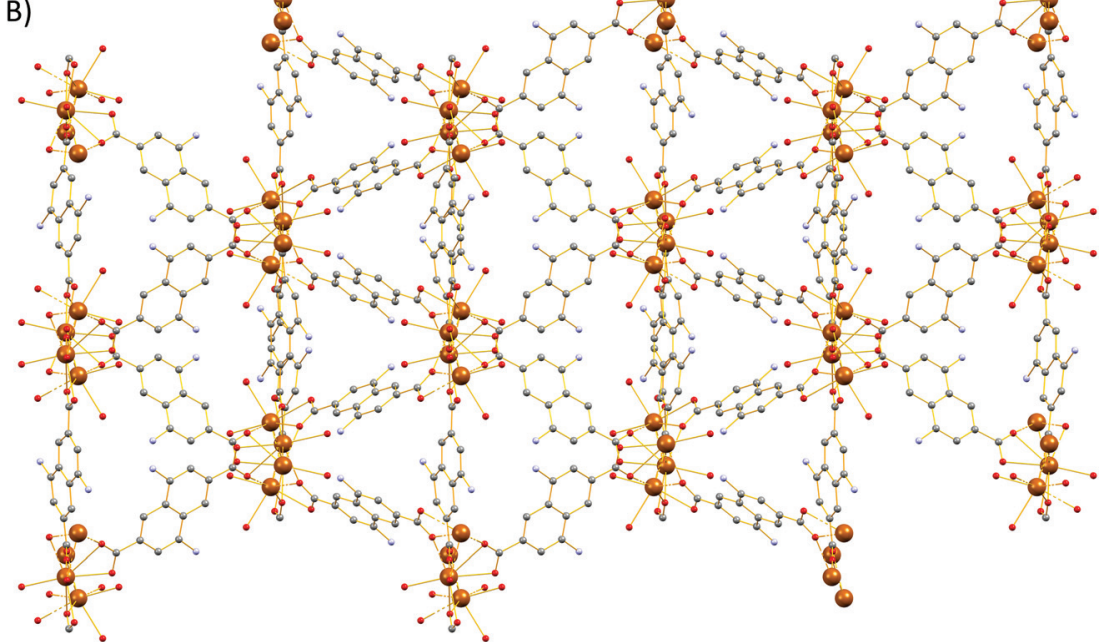

Fig. 3 Representation of the (A) SBU and (B) three-dimensional structure along the $\mathrm{C}$ axis of 2 . $\mathrm{H}$ atoms and solvent molecules were omitted for clarity. Colour code: Sr, brown; C, gray; O, red; N, blue. 
A)

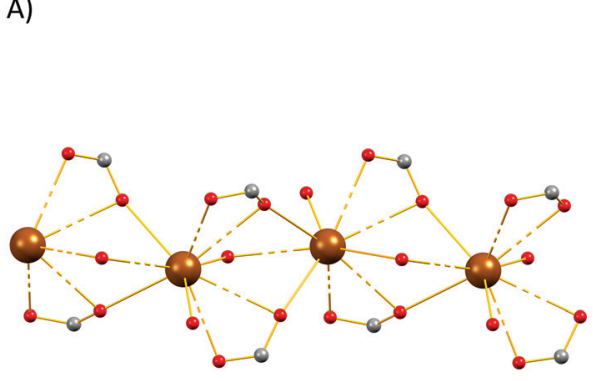

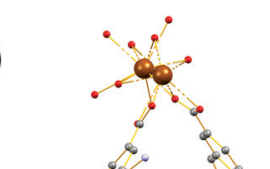

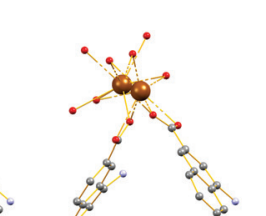

\section{.}

\section{Crystal structure of 4}

Single-crystal X-ray diffraction reveals that $\mathbf{4}$ crystallizes in the monoclinic $P 2_{1} / c$ space group (Table S1 $\dagger$ ). The SBU of 4 consists of an infinite rod $\left[\mathrm{Mg}_{2}(\mathrm{COO})_{4}\left(\mathrm{H}_{2} \mathrm{O}\right)_{1.75}(\mathrm{DMF})_{0.25}\right]$ unit (Fig. 5A) featuring two crystallographically independent $\mathrm{Mg}^{2+}$ ions (Mg1, Mg2). Mg1 is five-coordinated by five oxygen atoms to form a distorted square pyramid in which four oxygen atoms are from the carboxylate groups of the dicarboxylic ligands and another oxygen (O10) is from terminally coordinated solvent and was modeled as originating from a water molecule (75\% occupancy) and from the $\mathrm{C}=\mathrm{O}$ group of a DMF molecule (25\% occupancy). On the other hand, Mg2 ion is six-coordinated by oxygen atoms and each of them is ligated with five carboxylate groups which belong to four different carboxylate ligands and one oxygen atom (O9) which was modeled as originating from a coordinated water molecule and from the $\mathrm{C}=\mathrm{O}$ group of a terminal DMF ligand (50\% occupancy). The geometry around $\mathrm{Mg} 2$ is best described as a distorted octahedron. The three-dimensional structure of 4 is shown in Fig. 5B. From the topological view, $\mathrm{Mg} 1$ and $\mathrm{Mg} 2$ are bridged by three carboxylate groups to create a corner sharing dimer. These dimers are further bridged by a syn, anti-carboxylate thus creating a rod along $c$ (Fig. S19†). If we consider the carboxylate $\mathrm{C}$ atoms (C1, C7, C13, and C19) as the points of connection, then a corner sharing zig-zag chain of distorted trigonal bipyramids forms along the rod. These chains of distorted trigonal bipyramids are further linked by the naphthalene moities of the ligands to create a complex tetranodal network comprising three 5-coordinate and one 7-coordinate node. The point symbol of this net is $\left(3^{5} \cdot 4 \cdot 6^{2} \cdot 7^{2}\right)_{3}\left(3^{6} \cdot 6^{9} \cdot 7^{6}\right)$ and it is, as expected, unique so far.

\section{Thermal stability}

The thermal stability of compounds 1-8 was studied by thermogravimetric analysis on a Mettler-Toledo TGA/DSC1 instrument under a $\mathrm{N}_{2}$ flow of $50 \mathrm{~mL} \mathrm{~min}^{-1}$. The thermographs of 1-8 (Fig. S20-27†) data show weight losses starting from $25^{\circ} \mathrm{C}$ and ending at over $800{ }^{\circ} \mathrm{C}$ they involve the removal of the solvent molecules, followed by the collapse of the frameworks above $210^{\circ} \mathrm{C}$.

\section{Photophysical properties}

Compounds 1-8 were studied by steady-state fluorescence spectroscopy in the solid state at room temperature. The free ligands $\mathrm{H}_{2}$ ANDC and $\mathrm{H}_{2}$ DANDC were studied by UV-vis absorption and fluorescence spectroscopy in $\mathrm{DMF} / \mathrm{MeOH}$ mixed solvent systems.

The absorption spectra of the amino substituted ligands show strong absorptions in the UV region which can be assigned to fully allowed $\pi^{*} \leftarrow \pi$ transitions of the aromatic core (Fig. S30 $\dagger) .{ }^{85}$ The lowest energy absorption signals $\left(\lambda_{\max } \sim\right.$ $400 \mathrm{~nm}$ ) exhibited by $\mathrm{H}_{2}$ ANDC and $\mathrm{H}_{2}$ DANDC consist of broad peaks of moderate intensities $\left(\varepsilon \sim 3000 \mathrm{M}^{-1} \mathrm{~cm}^{-1}\right)$ which show only a slight blue shift upon changing the solvent from DMF to methanol (Fig. S31 and $32 \dagger$ ). The emission spectra of 
A)

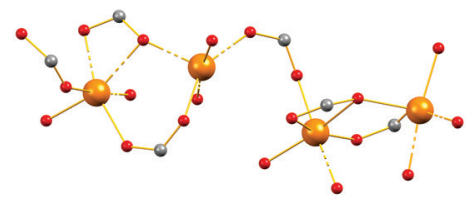

B)

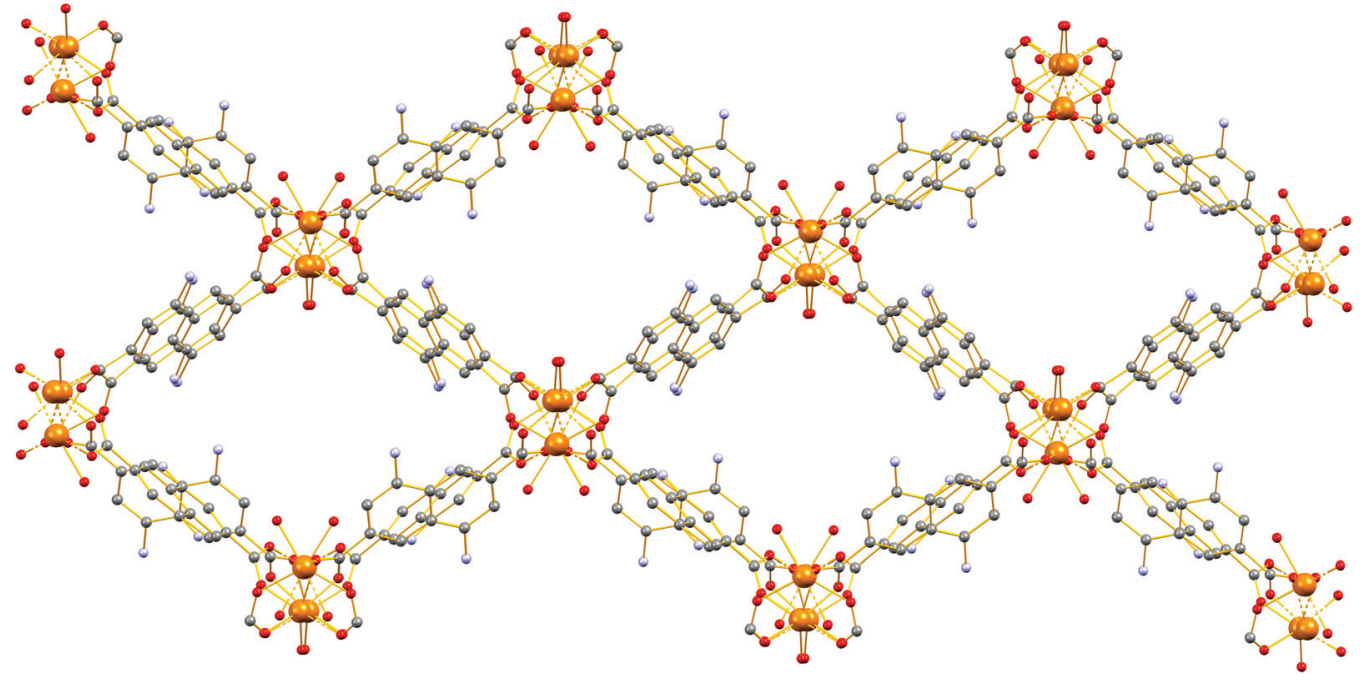

Fig. 5 Representation of the (A) SBU and (B) the three-dimensional structure along the $c$ axis of $4 . \mathrm{H}$ atoms and solvent molecules were omitted for clarity. Colour code: $\mathrm{Mg}$, brown; C, gray; O, red; N, blue.

$\mathrm{H}_{2} \mathrm{ANDC}$ and $\mathrm{H}_{2}$ DANDC in DMF/MeOH mixtures (ranging from pure DMF to pure $\mathrm{MeOH}$ ) upon selective excitation at the lowest energy absorption $\left(\lambda_{\text {exc }}=370 \mathrm{~nm}\right)$ can be seen in Fig. 6 and 7. The excitation spectra (Fig. S33 and $34 \dagger$ ) show excellent agreement with the UV-vis absorption spectra in both profile and tendency of the lowest energy absorption feature to undergo a slight blue shift upon increasing the polarity of the solvent system. $\mathrm{H}_{2}$ ANDC and $\mathrm{H}_{2}$ DANDC show similar emission profiles which undergo a significant red shift upon increasing the $\mathrm{MeOH}$ content of the solvent system $\left(\lambda_{\max }\right.$ values shift

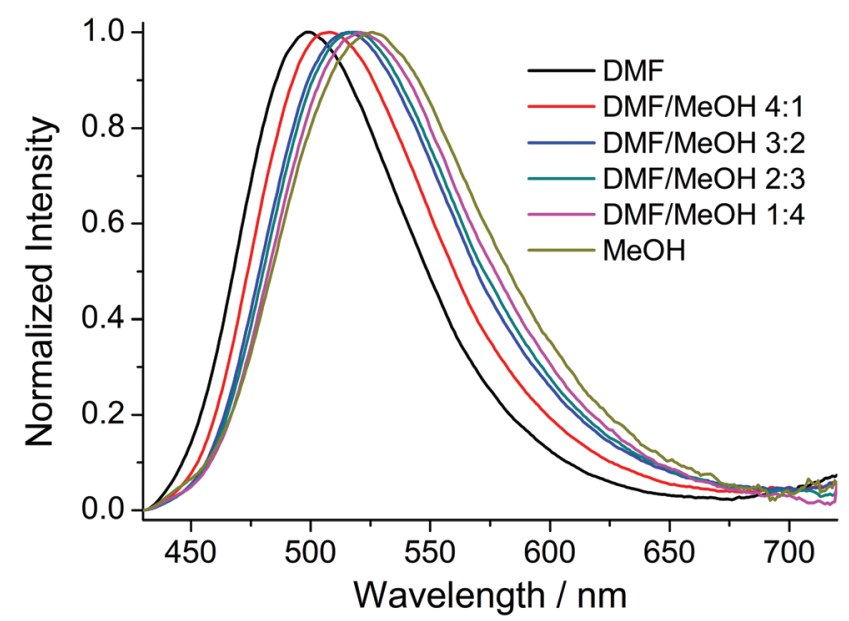

Fig. 6 Emission spectra of the $\mathrm{H}_{2} \mathrm{ANDC}$ ligand in $\mathrm{DMF} / \mathrm{MeOH}$ mixtures $\left(\lambda_{\mathrm{exc}}=370 \mathrm{~nm}\right)$. from 500 to $526 \mathrm{~nm}$ for $\mathrm{H}_{2} \mathrm{ANDC}$ and from 480 to $520 \mathrm{~nm}$ for $\mathrm{H}_{2}$ DANDC in DMF and MeOH respectively. The observed stabilization of the lowest energy ligand-based excited states as the polarity of the medium increases, is consistent with them being of charge transfer nature involving the excitation of an electron in a predominantly amino group orbital to an empty $\pi^{*}$ orbital of the aromatic core. ${ }^{85}$

Upon excitation at $370 \mathrm{~nm}$ MOFs 1-8 exhibit emission profiles that show good general agreement with those observed for the corresponding ligands (Fig. 8 and 9). This observation

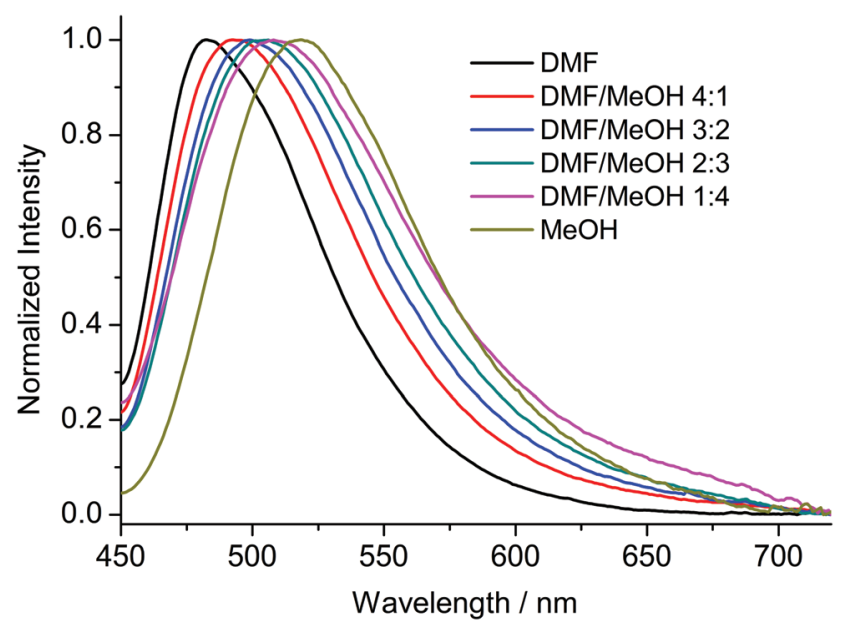

Fig. 7 Emission spectra of the $\mathrm{H}_{2}$ DANDC ligand in DMF/MeOH mixtures $\left(\lambda_{\text {exc }}=370 \mathrm{~nm}\right)$. 


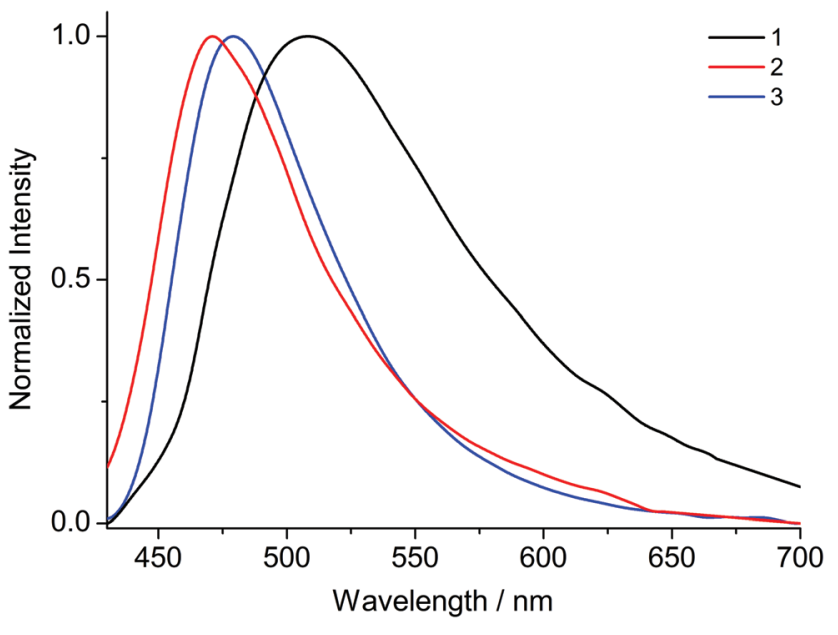

Fig. 8 Solid state emission spectra of $1-3\left(\lambda_{\text {exc }}=370 \mathrm{~nm}\right)$.

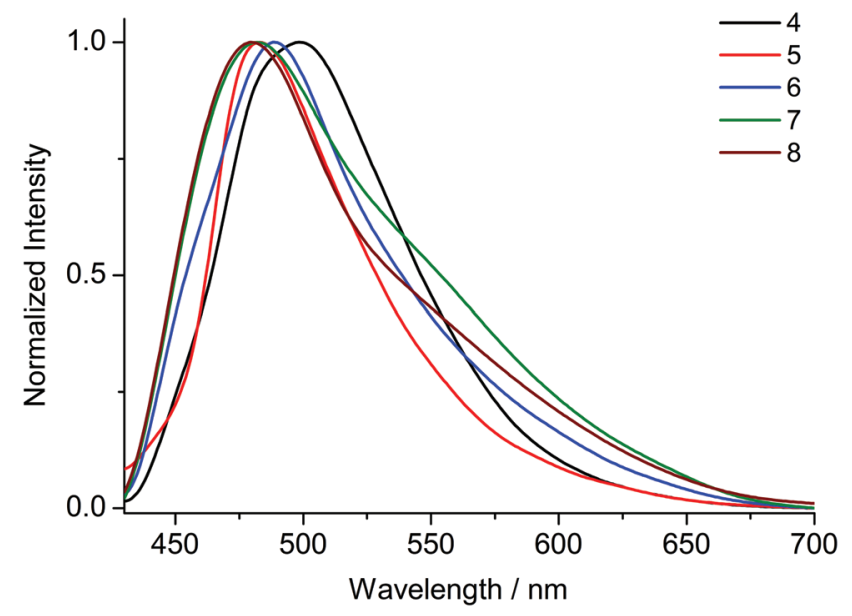

Fig. 9 Solid state emission spectra of 4-8 $\left(\lambda_{\text {exc }}=370 \mathrm{~nm}\right)$.

combined with the spectroscopically inert closed shell alkaline earth cations, confirms that the observed fluorescence is ligand-based. In the cases of the $\mathrm{ANDC}^{2-}$-based MOFs 1, 2 and 3 (Fig. 8), the emission maxima are at 509, 472 and $479 \mathrm{~nm}$ respectively. The significant red shift in the emission maximum of $\mathbf{1}$ compared to those of $\mathbf{2}$ and $\mathbf{3}$ can be possibly be assigned to a combination of structural and electrostatic factors related to the higher charge density of the $\mathrm{Ca}^{2+}$ ion relative to $\mathrm{Sr}^{2+}$ and $\mathrm{Ba}^{2+} \cdot{ }^{33}$ The stronger electron withdrawing effect of the $\mathrm{Ca}^{2+}$ cation possibly induces a stabilizing effect on the $\pi^{*}$ orbitals of the aromatic core of $\mathrm{ANDC}^{2-}$ thereby decreasing the energy of the intraligand charge transfer transition. Additionally, as demonstrated by the solvatochromism exhibited by the uncoordinated ligands, the emission energies of the organic linkers also depend on the immediate environment around their chromophores such as the existence and relative strength of hydrogen boding interactions. As a result, the observed emission energies are possibly the result of a finely balanced interplay between the above-mentioned factors. This is also reflected in the cases of the DANDC ${ }^{2-}$-based MOFs 4-8
(Fig. 9) $\left(4 \lambda_{\mathrm{em}}=499 \mathrm{~nm} ; 5 \lambda_{\mathrm{em}}=489 \mathrm{~nm} ; 6 \lambda_{\mathrm{em}}=483 \mathrm{~nm}\right.$; $7 \lambda_{\mathrm{em}}=482 \mathrm{~nm} ; 8 \lambda_{\mathrm{em}}=480 \mathrm{~nm}$ ) which generally show a less pronounced variation in their emission maxima. ${ }^{28}$

\section{Conclusion}

In summary, a series of eight alkaline earth MOFs 1-8 has been isolated by reacting chloride and nitrate salts of $\mathrm{Mg}^{2+}$, $\mathrm{Ca}^{2+}, \mathrm{Sr}^{2+}$ and $\mathrm{Ba}^{2+}$ with mono- and di-amino naphthalene dicarboxylate linkers. Five of the compounds, $\mathbf{1}$ and 5-8, display rarely encountered square $\mathrm{M}_{4}$ SBUs with either a disordered water molecule $(\mathbf{1}, \mathbf{5}, \mathbf{6})$ or a chloride ion $(7$ and $\mathbf{8})$ in the centre. In the cases of the chloride-bridged 7 and $\mathbf{8}$, the positions above and below the centre of the square plane are partially occupied by $\mathrm{M}^{2+}$ ions thereby creating $\mathrm{M}_{6}$ octahedra. MOFs 1, 5, 7 and 8 form 4-c peb nets which can be simplified to the 8-c bcu net, while 6 adopts the 4-c lta net which simplifies to the 8-c reo net. In contrast, MOFs 2, 3 and 4 also feature three dimensional networks with linear rod-shaped SBUs with the $\mathrm{Ba}^{2+}$ MOF 3 displaying an sra rod-net and MOFs 2 and 4 showing very complex rod-nets with so far unique topologies. Preliminary fluorescence spectroscopy studies showed that all the compounds show blue green fluorescence with profiles which bare close resemblance to the charge transfer-type emission of the free ligands. Further work exploring the coordination chemistry of amino substituted dicarboxylates and their potential applications as fluorescent sensors and light emitters is ongoing in our laboratory.

\section{Author contributions}

The manuscript was written through contributions of all authors. All authors have given approval to the final version of the manuscript.

\section{Conflicts of interest}

There are no conflicts to declare.

\section{Acknowledgements}

SD thanks the State Scholarships Foundation (IKY) for a doctoral research scholarship. This research is co-financed by Greece and the European Union (European Social Fund - ESF) through the Operational Programme "Human Resources Development, Education and Lifelong Learning" in the context of the project "Strengthening Human Resources Research Potential via Doctorate Research - 2nd Cycle" (MIS-5000432), implemented by the State Scholarships Foundation (IKY). GSP thanks the Special Account for Research Grants (SARG) of the National and Kapodistrian University of Athens (NKUA) for partial support and the Bodossaki Foundation for donating the TGA to NKUA. 


\section{References}

1 H.-C. Zhou, J. R. Long and O. M. Yaghi, Chem. Rev., 2012, 112, 673-674.

2 H. Furukawa, K. E. Cordova, M. O'Keeffe and O. M. Yaghi, Science, 2013, 341, 1230444.

3 M. O’Keeffe and O. M. Yaghi, Chem. Rev., 2012, 112, 675702.

4 J. A. Mason, M. Veenstra and J. R. Long, Chem. Sci., 2014, 5, 32-51.

5 D. Alezi, Y. Belmabkhout, M. Suyetin, P. M. Bhatt, Ł. J. Weseliński, V. Solovyeva, K. Adil, I. Spanopoulos, P. N. Trikalitis, A.-H. Emwas and M. Eddaoudi, J. Am. Chem. Soc., 2015, 137, 13308-13318.

6 H. Li, K. Wang, Y. Sun, C. T. Lollar, J. Li and H.-C. Zhou, Mater. Today, 2018, 21, 108-121.

7 M. Eddaoudi, J. Kim, N. Rosi, D. Vodak, J. Wachter, M. O'Keeffe and O. M. Yaghi, Science, 2002, 295, 469-472.

8 D.-X. Xue, Q. Wang and J. Bai, Coord. Chem. Rev., 2019, 378, 2-16.

9 J. Liu, L. Chen, H. Cui, J. Zhang, L. Zhang and C.-Y. Su, Chem. Soc. Rev., 2014, 43, 6011-6061.

10 V. P. Santos, T. A. Wezendonk, J. J. D. Jaén, A. I. Dugulan, M. A. Nasalevich, H.-U. Islam, A. Chojecki, S. Sartipi, X. Sun, A. A. Hakeem, A. C. J. Koeken, M. Ruitenbeek, T. Davidian, G. R. Meima, G. Sankar, F. Kapteijn, M. Makkee and J. Gascon, Nat. Commun., 2015, 6, 6451.

11 M. Zhao, S. Ou and C.-D. Wu, Acc. Chem. Res., 2014, 47, 1199-1207.

12 L. Jiao, Y. Wang, H.-L. Jiang and Q. Xu, Adv. Mater., 2018, 30, 1703663.

13 Y.-S. Kang, Y. Lu, K. Chen, Y. Zhao, P. Wang and W.-Y. Sun, Coord. Chem. Rev., 2019, 378, 262-280.

14 X. Li, B. Wang, Y. Cao, S. Zhao, H. Wang, X. Feng, J. Zhou and X. Ma, ACS Sustainable Chem. Eng., 2019, 7, 4548-4563.

15 S. Yuan, L. Feng, K. Wang, J. Pang, M. Bosch, C. Lollar, Y. Sun, J. Qin, X. Yang, P. Zhang, Q. Wang, L. Zou, Y. Zhang, L. Zhang, Y. Fang, J. Li and H.-C. Zhou, Adv. Mater., 2018, 30, 1704303.

16 S. Rapti, D. Sarma, S. A. Diamantis, E. Skliri, G. S. Armatas, A. C. Tsipis, Y. S. Hassan, M. Alkordi, C. D. Malliakas, M. G. Kanatzidis, T. Lazarides, J. C. Plakatouras and M. J. Manos, J. Mater. Chem. A, 2017, 5, 14707-14719.

17 S. Rapti, A. Pournara, D. Sarma, I. T. Papadas, G. S. Armatas, A. C. Tsipis, T. Lazarides, M. G. Kanatzidis and M. J. Manos, Chem. Sci., 2016, 7, 2427-2436.

18 P. Kumar, A. Pournara, K.-H. Kim, V. Bansal, S. Rapti and M. J. Manos, Prog. Mater. Sci., 2017, 86, 25-74.

19 L. Zhu, D. Sheng, C. Xu, X. Dai, M. A. Silver, J. Li, P. Li, Y. Wang, Y. Wang, L. Chen, C. Xiao, J. Chen, R. Zhou, C. Zhang, O. K. Farha, Z. Chai, T. E. Albrecht-Schmitt and S. Wang, J. Am. Chem. Soc., 2017, 139, 14873-14876.

20 S. A. Diamantis, A. Margariti, A. D. Pournara, G. S. Papaefstathiou, M. J. Manos and T. Lazarides, Inorg. Chem. Front., 2018, 5, 1493-1511.
21 Z. Hu, B. J. Deibert and J. Li, Chem. Soc. Rev., 2014, 43, 5815-5840.

22 W. P. Lustig, S. Mukherjee, N. D. Rudd, A. V. Desai, J. Li and S. K. Ghosh, Chem. Soc. Rev., 2017, 46, 3242-3285.

23 Y. Zhang, S. Yuan, G. Day, X. Wang, X. Yang and H.-C. Zhou, Coord. Chem. Rev., 2018, 354, 28-45.

24 H.-R. Fu, Y. Zhao, T. Xie, M.-L. Han, L.-F. Ma and S.-Q. Zang, J. Mater. Chem. C, 2018, 6, 6440-6448.

25 T. Gong, P. Li, Q. Sui, J. Chen, J. Xu and E.-Q. Gao, J. Mater. Chem. A, 2018, 6, 9236-9244.

26 T. He, Y.-Z. Zhang, X.-J. Kong, J. Yu, X.-L. Lv, Y. Wu, Z.-J. Guo and J.-R. Li, ACS Appl. Mater. Interfaces, 2018, 10, 16650-16659.

27 D. Banerjee, H. Wang, B. J. Deibert and J. Li, Alkaline Earth Metal-Based Metal-Organic Frameworks: Synthesis, Properties, and Applications, in The Chemistry of MetalOrganic Frameworks: Synthesis, Characterization, and Applications, ed. S. Kaskel, Wiley-VCH, Weinheim, 2016, vol. 1.

28 A. Douvali, G. S. Papaefstathiou, M. P. Gullo, A. Barbieri, A. C. Tsipis, C. D. Malliakas, M. G. Kanatzidis, I. Papadas, G. S. Armatas, A. G. Hatzidimitriou, T. Lazarides and M. J. Manos, Inorg. Chem., 2015, 54, 5813-5826.

29 A. Khansari, S. G. Telfer and C. Richardson, Cryst. Growth Des., 2019, 19, 268-274.

30 D. Briones, P. Leo, J. Cepeda, G. Orcajo, G. Calleja, R. Sanz, A. Rodríguez-Diéguez and F. Martínez, CrystEngComm, 2018, 20, 4793-4803.

31 S. A. Diamantis, A. D. Pournara, A. G. Hatzidimitriou, M. J. Manos, G. S. Papaefstathiou and T. Lazarides, Polyhedron, 2018, 153, 173-180.

32 A. Douvali, A. C. Tsipis, S. V. Eliseeva, S. Petoud, G. S. Papaefstathiou, C. D. Malliakas, I. Papadas, G. S. Armatas, I. Margiolaki, M. G. Kanatzidis, T. Lazarides and M. J. Manos, Angew. Chem., Int. Ed., 2015, 54, 16511656.

33 Z. H. Fard, Y. Kalinovskyy, D. M. Spasyuk, B. A. Blight and G. K. H. Shimizu, Chem. Commun., 2016, 52, 12865-12868.

34 F. Hu, Z. Di, M. Wu and J. Li, Dalton Trans., 2020, 49, 88368840 .

35 X.-Y. Li, L.-N. Ma, Y. Liu, L. Hou, Y.-Y. Wang and Z. Zhu, ACS Appl. Mater. Interfaces, 2018, 10, 10965-10973.

36 L. Asgharnejad, A. Abbasi, M. Najafi and J. Janczak, Cryst. Growth Des., 2019, 19, 2679-2686.

37 P. Leo, G. Orcajo, D. Briones, A. Rodríguez-Diéguez, D. Choquesillo-Lazarte, G. Calleja and F. Martínez, Dalton Trans., 2019, 48, 11556-11564.

38 C. Pan, J. Nan, X. Dong, X.-M. Ren and W. Jin, J. Am. Chem. Soc., 2011, 133, 12330-12333.

39 M. Usman, S. Mendiratta, S. Batjargal, G. Haider, M. Hayashi, N. Rao Gade, J.-W. Chen, Y.-F. Chen and K.-L. Lu, ACS Appl. Mater. Interfaces, 2015, 7, 2276722774.

40 R. M. P. Colodrero, P. Olivera-Pastor, E. R. Losilla, D. Hernández-Alonso, M. A. G. Aranda, L. Leon-Reina, J. Rius, K. D. Demadis, B. Moreau, D. Villemin, 
M. Palomino, F. Rey and A. Cabeza, Inorg. Chem., 2012, 51, 7689-7698.

41 X.-Y. Dong, X.-P. Hu, H.-C. Yao, S.-Q. Zang, H.-W. Hou and T. C. W. Mak, Inorg. Chem., 2014, 53, 12050-12057.

42 E. Papazoi, A. Douvali, S. Rapti, E. Skliri, G. S. Armatas, G. S. Papaefstathiou, X. Wang, Z.-F. Huang, S. Kaziannis, C. Kosmidis, A. G. Hatzidimitriou, T. Lazarides and M. J. Manos, Inorg. Chem. Front., 2017, 4, 530-536.

43 Y. Lin, C. Kong and L. Chen, RSC Adv., 2016, 6, 3259832614.

44 S. Xu and Y. Ni, Analyst, 2019, 144, 1687-1695.

45 Y. Fu, D. Sun, Y. Chen, R. Huang, Z. Ding, X. Fu and Z. Li, Angew. Chem., Int. Ed., 2012, 51, 3364-3367.

46 S. Mendiratta, M. Usman, T. W. Tseng, T. T. Luo, S. F. Lee, L. Zhao, M. K. Wu, M. M. Lee, S. S. Sun, Y. C. Lin and K. L. Lu, Eur. J. Inorg. Chem., 2015, 2015, 1669-1674.

47 S. Yuan, J.-S. Qin, H.-Q. Xu, J. Su, D. Rossi, Y. Chen, L. Zhang, C. Lollar, Q. Wang, H.-L. Jiang, D. H. Son, H. Xu, Z. Huang, X. Zou and H.-C. Zhou, ACS Cent. Sci., 2018, 4, 105-111.

48 S. Kampouri, T. N. Nguyen, M. Spodaryk, R. G. Palgrave, A. Züttel, B. Smit and K. C. Stylianou, Adv. Funct. Mater., 2018, 28, 1806368.

49 C. Queirós, A. M. G. Silva, B. de Castro and L. Cunha-Silva, Molecules, 2020, 25, 1353.

50 C.-X. Chen, Z. Wei, J.-J. Jiang, Y.-Z. Fan, S.-P. Zheng, C.-C. Cao, Y.-H. Li, D. Fenske and C.-Y. Su, Angew. Chem., Int. Ed., 2016, 55, 9932-9936.

51 C.-X. Chen, Z.-W. Wei, J.-J. Jiang, S.-P. Zheng, H.-P. Wang, Q.-F. Qiu, C.-C. Cao, D. Fenske and C.-Y. Su, J. Am. Chem. Soc., 2017, 139, 6034-6037.

52 R. K. Deshpande, J. L. Minnaar and S. G. Telfer, Angew. Chem., Int. Ed., 2010, 49, 4598-4602.

53 A. Khansari, M. R. Bryant, D. R. Jenkinson, G. B. Jameson, O. T. Qazvini, L. Liu, A. D. Burrows, S. G. Telfer and C. Richardson, CrystEngComm, 2019, 21, 74987506.

54 D. J. Lun, G. I. N. Waterhouse and S. G. Telfer, J. Am. Chem. Soc., 2011, 133, 5806-5809.

55 J. Sim, H. Yim, N. Ko, S. B. Choi, Y. Oh, H. J. Park, S. Park and J. Kim, Dalton Trans., 2014, 43, 18017-18024.

56 M. S. Yazdanparast, V. W. Day and T. Gadzikwa, Molecules, 2020, 25, 697.

57 M. Kaposi, M. Cokoja, C. H. Hutterer, S. A. Hauser, T. Kaposi, F. Klappenberger, A. Pöthig, J. V. Barth, W. A. Herrmann and F. E. Kühn, Dalton Trans., 2015, 44, 15976-15983.

58 M. S. Yazdanparast, V. W. Day and T. Gadzikwa, Molecules, 2020, 25, 697.

59 A. T. Nielsen, A. A. DeFusco and T. E. Browne, J. Org. Chem., 1985, 50, 4211-4218.

60 M. Almáši, V. Zeleňák, R. Gyepes, L. Zauška and S. Bourrelly, RSC Adv., 2020, 10, 32323-32334.

61 F. Hu, Z. Di, M. Wu and J. Li, Dalton Trans., 2020, 49, 88368840 .
62 X.-M. Zhang, J. Lv, F. Ji, H.-S. Wu, H. Jiao and P. v. R. Schleyer, J. Am. Chem. Soc., 2011, 133, 4788-4790.

63 S. Das, H. Kim and K. Kim, J. Am. Chem. Soc., 2009, 131, 3814-3815.

64 S. Ma, D. Yuan, X.-S. Wang and H.-C. Zhou, Inorg. Chem., 2009, 48, 2072-2077.

65 H. Chun, D. Kim, D. N. Dybtsev and K. Kim, Angew. Chem., Int. Ed., 2004, 43, 971-974.

66 S. Natarajan, S. Neeraj, A. Choudhury and C. N. R. Rao, Inorg. Chem., 2000, 39, 1426-1433.

67 K. Sharma, S. K. Gupta, A. Borah and R. Murugavel, Chem. Commun., 2019, 55, 7994-7997.

68 F. Wang, Y.-B. Shu, X. Bu and J. Zhang, Chem. - Eur. J., 2012, 18, 11876-11879.

69 T. Wu, X. Bu, J. Zhang and P. Feng, Chem. Mater., 2008, 20, 7377-7382.

70 D. F. Sava, V. C. Kravtsov, J. Eckert, J. F. Eubank, F. Nouar and M. Eddaoudi, J. Am. Chem. Soc., 2009, 131, 1039410396.

71 S. S. Mondal, A. Bhunia, A. Kelling, U. Schilde, C. Janiak and H.-J. Holdt, Chem. Commun., 2014, 50, 5441-5443.

72 Q.-R. Fang, G.-S. Zhu, Z. Jin, M. Xue, X. Wei, D.-J. Wang and S.-L. Qiu, Angew. Chem., Int. Ed., 2006, 45, 6126-6130.

73 Y.-Y. Qin, Q.-R. Ding, E. Yang, Y. Kang, L. Zhang and Y.-G. Yao, Inorg. Chem. Commun., 2015, 56, 83-86.

74 H. Reinsch, B. Bueken, F. Vermoortele, I. Stassen, A. Lieb, K.-P. Lillerud and D. De Vos, CrystEngComm, 2015, 17, 4070-4074.

75 H. Hayashi, A. P. Côté, H. Furukawa, M. O'Keeffe and O. M. Yaghi, Nat. Mater., 2007, 6, 501-506.

76 M. S. Jeong, Y. Kim and K. Seff, J. Phys. Chem., 1994, 98, 1878-1881.

77 M. J. Maple, E. F. Philp, A. M. Z. Slawin, P. Lightfoot, P. A. Cox and P. A. Wright, J. Mater. Chem., 2001, 11, 98104.

78 J. Yang, Y.-B. Zhang, Q. Liu, C. A. Trickett, E. GutiérrezPuebla, M. Á. Monge, H. Cong, A. Aldossary, H. Deng and O. M. Yaghi, J. Am. Chem. Soc., 2017, 139, 6448-6455.

79 V. Bon, I. Senkovska, I. A. Baburin and S. Kaskel, Cryst. Growth Des., 2013, 13, 1231-1237.

80 F. Drache, F. G. Cirujano, K. D. Nguyen, V. Bon, I. Senkovska, F. X. Llabrés i Xamena and S. Kaskel, Cryst. Growth Des., 2018, 18, 5492-5500.

81 Q.-R. Fang, D.-Q. Yuan, J. Sculley, W.-G. Lu and H.-C. Zhou, Chem. Commun., 2012, 48, 254-256.

82 N. L. Rosi, J. Kim, M. Eddaoudi, B. Chen, M. O'Keeffe and O. M. Yaghi, J. Am. Chem. Soc., 2005, 127, 1504-1518.

83 C. Serre, F. Millange, C. Thouvenot, M. Noguès, G. Marsolier, D. Louër and G. Férey, J. Am. Chem. Soc., 2002, 124, 13519-13526.

84 K. Barthelet, J. Marrot, D. Riou and G. Férey, Angew. Chem., Int. Ed., 2002, 41, 281-284.

85 V. Balzani, P. Ceroni and A. Juris, Photochemistry and Photophysics: Concepts, Research, Applications, Willey-VCH, Weinheim, 2014. 